\section{A PRESENÇA DE ANTHONY GIDDENS NA PRODUÇÃO CIENTÍFICA DA EDUCAÇÃO FíSICA BRASILEIRA: ENTRE A REFLEXÃO E O DESLIZE}

\author{
THE PRESENCE OF ANTHONY GIDDENS IN SCIENTIFIC PRODUCTION OF \\ BRAZILIAN PHYSICAL EDUCATION: BETWEEN REFLECTION AND SLIP
}

\author{
LA PRESENCIA DE ANTHONY GIDDENS EN LA PRODUCCIÓN CIENTÍFICA \\ DE LA EDUCACIÓN FÍSICA BRASILEÑA: ENTRE LA REFLEXIÓN Y EL \\ DESLIZAMIENTO
}

\section{Gabriel Carvalho Bungenstab*}

Palavras chave: Educação Física. Epistemologia. Modernidade.

\begin{abstract}
Resumo: O objetivo deste artigo é mapear a presença do sociólogo Anthony Giddens na produção científica do campo da Educação Física (EF) brasileira e analisar de que maneira suas contribuições teóricas aparecem na área. Este texto apresenta a descrição que Giddens faz sobre a sociedade moderna reflexiva e suas reconfigurações relacionadas ao agente/estrutura. Feito isso, o texto se ocupará de realizar um levantamento bibliográfico nos principais periódicos da área a fim de analisar aqueles artigos que referenciaram Giddens. Aponta, por fim, que: 1) há pouco diálogo entre a EF e o sociólogo inglês e 2) a maioria dos textos produzidos pela área não utiliza Giddens de maneira reflexiva, cometendo, assim, deslizes teóricos.
\end{abstract}

Abstract: This article maps the presence of sociologist Anthony Giddens in Brazilian scientific production in the field of Physical Education (PE) and analyzes how his theoretical contributions appear in the area. This text presents Giddens' description of modern reflective society and its reconfigurations related to agent/structure. Afterwards, a bibliographical survey is conducted in the main journals of the area in order to analyze articles referencing Giddens. Finally, it points out that 1) there is little dialogue between $\mathrm{PE}$ and the English sociologist and 2) most of the texts produced by the area do not use Giddens in a reflexive way, thus committing theoretical slips.

Resumen: El objetivo de este artículo es mapear la presencia del sociólogo Anthony Giddens en la producción científica del campo de la Educación Física (EF) brasileña y analizar de qué manera sus contribuciones teóricas aparecen en el área. Este texto presenta la descripción que Giddens hace sobre la sociedad moderna reflexiva y sus reconfiguraciones relacionadas al agente/estructura. Hecho esto, el texto se ocupará por realizar un levantamiento bibliográfico en los principales periódicos del área a fin de analizar aquellos artículos que referenciaron a Giddens. Por último, apunta que: 1) hay poco diálogo entre la EF y el sociólogo inglés y 2) la mayoría de los textos producidos por el área no utilizan Giddens de manera reflexiva, cometiendo, así, deslices teóricas.
*Universidade Estadual de Goiás Goiânia, GO, Brasil. E-mail: gabrielcarv@msn.com

Recebido em: 01-04-2017 Aprovado em: 14-06-2018

DOI: https://doi.org/10.22456/1982-8918.81631 (c) (1) (8) Licence 


\section{INTRODUÇÃO}

A discussão epistemológica da Educação Física (EF) brasileira assumiu diferentes contornos ao longo das últimas décadas e estabeleceu diálogos com diversas áreas do conhecimento, inclusive com a Sociologia1. Na década de 1980, segundo Lima (1999), a crise de identidade da EF permeou tanto as questões políticos-ideológicas como aquelas relacionadas ao debate epistemológico. Este último se estendeu até o fim década de 1990, centrando suas discussões basicamente entre a vertente científica (que acreditava no caráter verdadeiro da ciência como legitimadora da EF) e a vertente pedagógica (defendia que a EF não era uma ciência, contudo, estaria interessada nela a partir de uma relação horizontal de produção e reflexão do conhecimento).

Para Almeida, Bracht e Vaz (2012), é nos idos dos anos 2000 que acontece uma (re) descrição epistemológica, dividida basicamente entre os modernos e os "pós-modernos". Os autores apontam que as perspectivas materialistas histórico-dialéticas acabam desqualificando as novas perspectivas contemporâneas. Para eles, existem inúmeros autores que não se encaixam em matrizes teóricas específicas, como, por exemplo: Michel Foucault, Zygmunt Bauman, Richard Rorty e Anthony Giddens.

O campo da EF tem lançado mão de autores específicos da Sociologia com o intuito de entender os seus limites e possibilidades. Medeiros e Godoy (2009) realizaram pesquisa objetivando mapear a presença de Pierre Bourdieu e Norbert Elias na Revista Brasileira de Ciências do Esporte (RBCE) entre os anos de 1979 até 2007. As autoras concluíram que as construções teóricas desses sociólogos estão qualitativamente aumentando na EF, principalmente no que tange ao debate sobre a Sociologia do Esporte. Atualmente, Souza e Marchi Junior (2017) também discutem as contribuições de Bourdieu para compreender os fenômenos esportivos modernos. A partir das contribuições dos autores supracitados é possível vislumbrar diálogos com outros sociólogos contemporâneos, sobretudo quando se reconhece que ainda há uma lacuna na produção da EF em relação ao uso de determinados pensadores. Nesse sentido, além das contribuições de Bourdieu e Elias, a Sociologia desenvolvida por Anthony Giddens também pode auxiliar o campo da EF, especificamente no que tange à produção do conhecimento no século XXI? O objetivo deste artigo é mapear a presença de Giddens na produção científica do campo da EF brasileira e analisar de que maneira suas contribuições teóricas aparecem na área.

É partindo das reflexões da Sociologia moderna que Giddens desenvolveu suas abordagens teóricas, sobretudo no que se refere à relação existente entre os indivíduos e as instituições. Giddens possui uma leitura crítica da modernidade e, em vários momentos, faz análises em que as discussões sobre o corpo, a identidade e as instituições estão em pauta. Isso justifica sua escolha, pois, se há entre a EF e a Sociologia uma forte imbricação, as análises feitas por Giddens podem nos oferecer importantes ideias para compreender questões singulares da EF na atualidade.

A opção pelo recorte temporal a partir do século XXI se justifica por dois fatores: 1) compreendo, de acordo com Santos (2010), que neste período histórico a produção do conhecimento e as potencialidades tecnológicas fizeram emergir o sentimento de descompasso e de insegurança diante de tudo já produzido até então, fazendo emergir novos paradigmas, e 2) se intensifica, a partir do século XXI, a ampliação da produção da EF para além das dissertações e teses, com foco, também, em artigos científicos publicados em revistas eletrônicas. Dito isso, o presente artigo é dividido em três momentos: 1) apresentação da teoria sociológica de

1 Destaco as contribuições pioneiras de Bracht (2005). 
Giddens; 2) mapeamento e análise da presença de Giddens na produção científica da EF a partir do século XXI e 3) conclusões.

\section{A SOCIEDADE CONTEMPORÂNEA PELAS LENTES DE ANTHONY GIDDENS}

Anthony Giddens é um sociólogo britânico nascido em 1938, autor de mais de 30 livros e inúmeros artigos. Por meio de suas análises reflexivas e críticas, podemos afirmar que Giddens não só realiza uma reinterpretação da modernidade, mas também procura reconstruir a teoria social a partir da noção de reflexividade e de agente/estrutura. A discussão a seguir apresenta as contribuições de Giddens sobre a modernidade, seguidas das suas análises a respeito da teoria social. ${ }^{2}$

Podemos entender a modernidade como um período histórico/social/cultural/econômico que se refere a um estilo, um costume de vida e uma organização social que emergiu na Europa a partir do século XVII. Os modos de vida que foram produzidas pela modernidade desvencilharam os indivíduos de todos os tipos de ordens sociais que existiam até então, fazendo emergir a era da globalização. Segundo Giddens (1991, 2002), a globalização se define como uma intensificação das relações sociais, fazendo acontecimentos locais se tornarem globais e vice-versa. De acordo com o sociólogo britânico, o surgimento da sociedade moderna, em detrimento da sociedade tradicional, gerou uma série de descontinuidades.

Dentre essas, destacam-se as mudanças no plano do ritmo da vida e das relações sociais, bem como os surgimentos das instituições modernas (como o Estado e a escola). Com o advento do Estado foi possível classificar todos os níveis da vida cotidiana, inclusive aqueles referentes aos horários de lazer/trabalho e ao espaço-tempo. Ao defender a ideia de descontinuidade da modernidade, Giddens $(1991,2002)$ enfatiza a importância das instituições sociais modernas e acredita que pensar a partir delas é uma forma de entender a ruptura com o passado e o entendimento do presente. Segundo ele, o desenvolvimento das instituições (e de seus papéis sociais) fez com que os indivíduos passassem a viver com intenso sentimento de segurança. Assim, as instituições desencaixadas do tempo-espaço modificaram a ideia de local/global e transformaram a vida dos indivíduos, que, até então, era pautada por hábitos e mudanças de cunho local. Afetando a vida de um número maior de indivíduos, as instituições modernas conectaram o local/global e interferiram de maneira igual na vida de diferentes pessoas, em diversas localidades.

Além das criações das instituições modernas, outros mecanismos foram criados a fim de fazer a sociedade acreditar no projeto da modernidade. Dentre eles, Giddens (1991, 2002) destaca o surgimento das fichas simbólicas e dos sistemas peritos. As fichas simbólicas surgem como ferramenta para homogeneizar e facilitar a economia das crescentes cidades, traduzidas pela figura do dinheiro. Já os sistemas peritos são entendidos como sistemas de excelência técnica e profissional que, de forma especializada, vão influenciar as ações da vida cotidiana dos indivíduos, gerando um sentimento de confiança. Desse modo, o sistema perito é reconhecido como legítimo e irrealizável pelo próprio indivíduo, sobretudo quando ele percebe que não pode viver sem este.

Giddens (1991) ainda vai dizer que a modernidade se constitui por meio de quatro dimensões institucionais básicas que se relacionam entre si. São elas: o capitalismo

2 Esta discussão possibilitará uma melhor compreensão dos usos que o campo da EF faz de Giddens (que serão analisados posteriormente) 
(acumulação do capital no contexto de trabalho e mercado de produtos competitivos), o industrialismo (transformação da natureza e desenvolvimento do "ambiente criado"), o poder militar (industrialização da guerra e controle dos meios de violência) e a vigilância (controle da informação e supervisão social). Segundo Giddens (1991), o mecanismo da vigilância desenvolve papel sintomático na vida dos indivíduos, controlando aquilo que eles podem fazer e contribuindo para o fortalecimento do capitalismo. Essa vigilância, quando feita por meio das instituições, pode associar-se aos mecanismos dos sistemas peritos.

Giddens (2009), além de realizar uma releitura da modernidade, propõe uma reconstrução das análises sociais a partir da "teoria da estruturação", reconhecendo que essa é menos a experiência do ator individual e mais as práticas sociais que são ordenadas dentro do espaço-tempo. Desse modo, ao analisar a presença das estruturas e das instituições na vida dos indivíduos, deve-se levar em conta a ação do sujeito, que, por sua vez, é dotada de "reflexividade" dentro de um processo que está situado em uma temporalidade. Devemos nos atentar ao fato de que Giddens trabalha sob uma perspectiva dialética, logo, não vê o sujeito simplesmente como uma "marionete social", distanciado da autonomia de suas ações. Para ele (2009, p. 5), devemos estar cientes a respeito de duas formas de reducionismo,

Uma delas é a concepção redutiva das instituições, a qual, ao procurar mostrar o fundamento das instituições no inconsciente, não deixa campo suficiente para a operação de forças sociais autônomas. A segunda forma é uma teoria redutiva da consciência, a qual, querendo mostrar quanto da vida social é governado por correntes sombrias fora do alcance da consciência dos atores, não pode apreender adequadamente 0 nível de controle que os agentes estão caracteristicamente aptos a manter de modo reflexivo sobre sua própria conduta.

Para Giddens (2009), muito da nossa conduta humana não é diretamente motivado, assim, melhor seria afirmarmos que o indivíduo (agente) age sobre as instituições (mundo social) e as instituições (mundo social) agem sobre o indivíduo (agente). 0 sociólogo britânico ainda vai dizer que não podemos pensar nas estruturas de dominação apenas na forma de instituições produtoras de "corpos dóceis". Para ele, os sistemas sociais que apresentam continuidade no espaço e no tempo são permeados por relações de autonomia e dependência entre os indivíduos e sua coletividade na interação social. Mesmo na forma de dependência, os indivíduos podem interferir e influenciar as atividades dos sistemas superiores. Giddens (2009) chamou isso de dialética do controle nos sistemas sociais.

Nesse sentido, Giddens vai diferenciar os princípios estruturais das instituições. As instituições, para ele, são práticas que possuem maior extensão espaço-temporal dentro da reprodução das totalidades sociais. É dentro das práticas institucionalizadas que aparecem as maiores quantidades de regras (procedimentos de ação, aspectos da prática cotidiana). Nesse sentido, torna-se interessante pensar na relação dos indivíduos (agentes) com as instituições que surgiram na modernidade (alta), com o intuito de oferecer uma solidez e um projeto seguro de futuro, através da vida e das ações cotidianas dos indivíduos, perpassando as barreiras geográficas e geracionais. Podemos dizer, então, que o indivíduo pelas lentes de Giddens tem maior liberdade para atuar na construção de suas ações em sociedade. As estruturas condicionam a ação dos atores, fornecendo-lhe instrumentos para que aja por meio de regras e recursos específicos. Pode-se concluir esta apresentação de Giddens afirmando que ele tenta reconstruir a teoria social clássica na medida em que procura dialogar com os aspectos microssociais (agente) e macrossociais (estrutura) a partir das novas configurações surgidas na sociedade. No entanto, como essas reflexões aparecem no campo da EF? 


\section{OS DIÁLOGOS ENTRE A SOCIOLOGIA DE ANTHONY GIDDENS E O CAMPO DA EDUCAÇÃO FÍSICA}

Foi realizado, no presente texto, um levantamento bibliográfico com a intenção de compreender como Giddens é referenciado no campo da EF, em termos de artigos científicos. Concorda-se com Lakatos e Marconi (2006) quando estes afirmam que pesquisar por meio de um levantamento bibliográfico não significa apenas realizar uma revisão daquilo que já foi produzido, mas, sim, suscitar diferentes enfoques e propor abordagens inovadoras. Esse movimento foi construído da seguinte maneira: 1) mapear, quantitativamente, o número de referências a Giddens; e 2) diagnosticar de que maneira os pensamentos deste sociólogo têm sido utilizado no campo da EF.

As revistas foram escolhidas a partir da classificação Webqualis/Capes. Nesse sentido, foi realizado um primeiro mapeamento a fim de identificar as dez revistas oriundas do campo da EF com as melhores avaliações. Percebeu-se que não há nenhuma revista avaliada como A1; uma revista (Movimento) avaliada como A2; cinco revistas (Motricidade, Motriz, RBCE, Revista Brasileira de Educação Física e Revista de Educação Física da UEM) avaliadas como B1 e quatro periódicos (Licere, Motrivivência, Pensar a Prática e Revista Brasileira de Atividade Física e Saúde) avaliados como B2. A partir disto, foram utilizados quatro critérios para escolha das revistas a serem pesquisadas: 1) que estabelecessem diálogo com o campo das Ciências Humanas e da Sociologia; 2) que publicassem seus artigos originalmente em língua portuguesa; 3) com estratos Qualis/Capes diferentes, ou seja: pelo menos uma revista de cada estrato, levando em consideração a heterogeneidade dos periódicos e entendendo que há produção de qualidade em revistas de estratos "inferiores"; e 4) revistas que atualmente têm publicações quadrimestrais (na intenção de captar um maior número de publicações e variedade de autores).

Após essa seleção foram escolhidas quatro revistas: Motrivivência, RBCE, Pensar a Prática e Movimento. Inicialmente foram mapeados aqueles artigos que fizeram referência a Giddens a partir do ano de 2001 até o ano de 2017. Esse mapeamento se deu por meio de uma busca profunda analisando o referencial teórico de todos os artigos publicados (Quadro 1). Em seguida, focou-se na análise qualitativa procurando compreender como Giddens foi citado e quais diálogos que os autores dos textos estabelecem (ou não) com sua obra. Para tal, foi necessário realizar a leitura completa de todos os 38 textos mapeados. Com esta análise 0 leitor perceberá (Quadro 3), na discussão a seguir, que Giddens é utilizado pelo campo da EF de duas maneiras: ora como uma leitura geral para compreender a sociedade; ora como leitura específica para dialogar com categorias relacionadas à EF.

Quadro 1 - Número de artigos que referenciam Anthony Giddens em cada periódico a partir do século XXI (2001-2017)

\begin{tabular}{|c|c|c|c|c|c|}
\hline Ano/Periódicos & Motrivivência & Pensar a Prática & Movimento & RBCE & TOTAL $^{3}$ \\
\hline $\begin{array}{c}\text { Referências a Giddens } \\
\text { de 2001 até 2017 }\end{array}$ & 4 & 9 & 17 & 8 & 38 \\
\hline $\begin{array}{c}\text { Total de publicações de } \\
2001 \text { até } 2017^{4}\end{array}$ & 556 & 694 & 840 & 799 & 2.889 \\
\hline
\end{tabular}

Fonte: construção do autor

3 Foram encontrados 12 artigos escritos em língua espanhola que citaram Giddens. Esses textos foram desconsi-derados, pois o objetivo aqui é compreender a relação deste sociólogo especificamente com a produção da EF brasileira.

4 As resenhas não foram incluídas. 
Percebe-se, de acordo com o quadro acima, que 38 artigos produzidos no cenário brasileiro referenciaram Giddens em suas pesquisas. Isso nos permite concluir que neste século a teoria desenvolvida pelo sociólogo inglês foi quantitativamente pouco utilizada pelo campo da EF. Se analisarmos de maneira percentual, nota-se que Giddens foi referenciado em apenas $1,3 \%$ do total de artigos publicados nesses quatro periódicos. Num primeiro movimento analítico, poderíamos afirmar que a teoria desenvolvida por Giddens não é utilizada pelo campo da EF, pois o que esse autor descreveu sobre a sociedade não faz relação direta com as discussões travadas neste campo, principalmente aquelas debatidas no cenário brasileiro. Por outro lado, poderíamos também supor que a pouca relação entre Giddens e a EF se deve ao fato de esta última ainda não conseguir fazer associações interessantes com aquilo desenvolvido pelo primeiro. Afinal, quais são os limites e as possibilidades que realmente findam a presença ou a não presença de Giddens em nossa área? Para responder esta indagação, torna-se importante analisar, também, quais são as obras mais citadas de Giddens e de que maneira elas são usadas nos textos (Quadro 2).

Quadro 2 - Relação quantitativa das obras de Giddens citadas pelos artigos analisados.

\begin{tabular}{|c|c|}
\hline Obras referenciadas $^{5}$ & Número de referências \\
\hline Modernidade e identidade & 20 \\
\hline As consequências da modernidade & 17 \\
\hline $\begin{array}{l}\text { Terceira Via: A Terceira Via. Reflexões sobre o impasse político atual e o } \\
\text { futuro da social-democracia }\end{array}$ & 2 \\
\hline Terceira Via e seus críticos & 2 \\
\hline A constituição da sociedade & 2 \\
\hline Teoria Social Hoje & 2 \\
\hline $\begin{array}{l}\text { Transformação da intimidade: sexualidade, amor e erotismo nas } \\
\text { sociedades modernas. }\end{array}$ & 2 \\
\hline
\end{tabular}

Fonte: construção do autor

Vemos, com o quadro acima, que as obras Modernidade e identidade e Consequências da modernidade são as mais referenciadas. Quais as consequências que essas duas obras têm para a EF? Elas são suficientes para estabelecermos um diálogo interdisciplinar da área com o sociólogo? Há mais citações referentes à obra Modernidade e identidade, fato que demonstra a tentativa de aproximação do campo com os conceitos do autor, uma vez que nesse livro Giddens (2002) estabelece um diálogo entre o corpo e a constituição da identidade na modernidade reflexiva. Nesse sentido, ele acredita ser fundamental compreender como as identidades são constituídas em um mundo onde as instâncias tradicionais já não são mais as protagonistas e o indivíduo assume papel importante na constituição do seu "eu". Segundo Giddens (2002, p. 36):

As transformações na autoidentidade e a globalização, como quero propor, são os dois polos da dialética do global e do local nas condições da alta modernidade. Em outras palavras, mudanças em aspectos íntimos da vida pessoal estão diretamente ligadas ao estabelecimento de conexões sociais de grande amplitude.

5 A obra A vida em uma sociedade pós-tradicional teve apenas uma citação e, por isso, não foi inserida no qua-dro. Giddens, em sua dissertação de mestrado, analisou a presença do esporte na Inglaterra. Esta obra aparente-mente não causou impactos para o campo da EF brasileira, sendo citada apenas uma vez por Souza e Marchi Junior (2010). 
Assim, a autoidentidade passa a ser constituída numa relação constante entre 0 indivíduo e as instituições modernas. Para Giddens (2002), a sociedade atual tende a segregar a experiência e o surgimento de especialistas/conselheiros torna-se perigoso para o exercício da reflexividade do indivíduo e sua emancipação. É analisando a relação corpo/agência que Giddens (2002) nos mostra que o corpo também age em diferentes espaços sociais, logo, como bem nos alerta Gomes, Almeida e Vaz (2009), a ação humana torna-se fundamental para compreender tanto os momentos de mudanças sociais como aqueles momentos de reprodução. Após o mapeamento/análise realizado nos quadros 1 e 2 , destacam-se dois tipos de leituras realizadas pelo campo da EF a partir das obras de Giddens (quadro 3).

Quadro 3 - Tipo de leitura realizada pela EF a partir do diálogo com a teoria de Giddens

\begin{tabular}{|c|c|c|}
\hline Leitura Geral & Leitura Específica & TOTAL \\
\hline $29(76 \%)$ & $9(24 \%)$ & $38(100 \%)$ \\
\hline
\end{tabular}

Fonte: construção do autor

Entende-se por leitura geral aquelas citações e menções que fizeram uma leitura da sociedade, porém, sem relação direta com o campo da EF; por leitura específica, aquelas citações que estão relacionadas ao campo da EF. Os artigos de Silva e Correa (2008), Gomes (2006, 2009), Gomes, Vaz e Assmann (2010), Gomes, Pich e Vaz (2006), Pinto et al. (2012), Teixeira, Freitas e Caminha (2014), Forell e Stigger (2017) e Souza (2014) se esforçaram em estabelecer, a partir de uma leitura específica, diálogos entre a obra de Giddens e as discussões sobre o corpo e sobre as políticas públicas voltadas para o esporte.

Gomes (2006, 2009) 6 aborda como o risco é espalhado em diversos espaços sociais na modernidade tardia, fazendo com que a busca por uma vida saudável (sem riscos) seja responsabilidade individual. Desse modo, o indivíduo precisar ter capacidade reflexiva suficiente para escolher um dentre os diversos sistemas peritos e conselheiros midiáticos. Gomes, Vaz e Assmann (2010) demonstraram como os editores de uma determinada revista de saúde produzem discursos, por meio de especialistas, que são reflexivamente confiáveis aos olhos dos seus leitores. Aqui vale a pena relembrar Giddens (2009) quando ele defende a ideia de que tanto a ação como o pensamento têm influência ímpar nas práticas sociais. Desse modo, as práticas sociais são redefinidas de acordo com as informações recebidas de forma renovada sobre as próprias práticas. Assim, preocupa-se menos com as justificativas tradicionais e mais com o conhecimento que existe em uma determinada prática ou numa relação institucionalizada, que pode ser alterada a qualquer momento.

Como bem ressalta Setton (2002, p. 68): "A reflexividade moderna consiste no fato de que as práticas sociais são frequentemente examinadas à luz de informações renovadas sobre essas práticas, podendo alterar sempre seu caráter". Nesse sentido, a reflexividade surge quando suas ações e práticas não são influenciadas pelas instituições simplesmente por seu caráter tradicional ou autoritário, mas, sim, porque esses novos conselheiros possibilitam um "conhecimento" que se torna plausível para a constituição cultural, gerando, assim, sentimento de segurança coletiva. Para Gomes (2009, p. 6), "O que está colocado é a necessidade de ter

6 Ivan Marcelo Gomes é o pesquisador, dentre o mapeamento realizado, que mais citou Giddens neste século, aparecendo como autor (e coautor) em cinco artigos de todos aqueles analisados. 
que escolher, de ter que optar, de ter que defender o corpo. As escolhas tornam-se uma espécie de imperativo". Vale ressaltar, nesse aspecto, as referências que Gomes, Vaz e Assmann (2010) fazem de Giddens (2002) ao citarem duas formas de defesa e responsabilização do corpo, uma voltada para o consumismo superficial e outra ligada à sensação de segurança ontológica (estabilidade e integração). Giddens (2002) parece concordar mais com a segunda, porém, para Gomes, Vaz e Assmann (2010, p. 129):

Parece que encontramos aí um ponto frágil na argumentação giddensiana, ao relativizar a pressão exercida pelos modelos de estilo de vida, veiculados pela mídia na sociedade de consumo. 0 estilo de vida saudável oferecido pelo caderno Equilíbrio é mais um dos inúmeros espaços de divulgação com o suporte de especialistas que reforçam determinados imperativos, neste caso, o imperativo e o padrão do que é ser saudável. A sensação de segurança oferecida pelo modelo de vida equilibrada no caderno reforça um determinado modelo e que, mesmo em constante revisão, sugere uma vida mais prazerosa para aqueles que se envolverem com essa tarefa.

Gomes, Vaz e Assmann (2010) concluem que as relações entre os sistemas peritos/ conselheiros modernos e os indivíduos não se dão apenas no âmbito da segurança ontológica, mas também estão atreladas à noção de risco, insegurança e consumo. Aliás, este diagnóstico é similar aquele realizado por Pinto et al. (2012).

Diferente do que concluíram Gomes, Vaz e Assmann (2010), pesquisa realizada por Teixeira, Freitas e Caminha (2014) com 30 mulheres frequentadoras de uma academia em Recife não demonstrou uma responsabilização do corpo voltada para a noção de risco, insegurança e consumo, mas, sim, que a procura do corpo belo é uma forma de se sentir integrado socialmente e reconhecer a si no outro. Para suas frequentadoras, a academia funciona como uma nova instituição que também renova a confiança social. Tal pesquisa reforça a ideia de Giddens (2002) quando ele aponta alguns diálogos interessantes sobre 0 corpo/saúde no sentido de pensá-lo também no que tange à dialética do global/local. Exemplo disso são as novas relações estabelecidas entre o corpo e a doença. Outrora a medicina moderna detinha o poder sobre as definições de saúde e seus tratamentos; hoje as chamadas "terapias alternativas" (como as academias de ginástica) ganham destaque, transformando 0 paciente em um ser ativo e "completo".

Já Forell e Stigger (2017) e Souza (2014) apontam outra maneira de relacionar Giddens com o campo da EF, mais precisamente tentando estabelecer um diálogo entre aquilo que 0 sociólogo chamou de "Terceira Via" e as políticas públicas de esporte. Com a ideia da terceira via, Giddens (2001) buscou reformular teorias políticas com a tentativa de unir tanto perspectivas socialistas (de esquerda) como as de cunho conservador (de direita). Nesse sentido, Giddens defende que os cidadãos devem transformar suas relações no que diz respeito às políticas estatais e, uma vez que são beneficiados por estas políticas, também devem realizar retribuições sociais. Souza (2014) faz críticas a essa perspectiva giddensiana ressaltando que a terceira via, ao reduzir as contradições existentes entre as classes, responsabiliza os indivíduos (e seus grupos) e delega papel protagonista às políticas públicas como aquelas voltadas para o esporte que, no fundo, irão reproduzir as relações de dominação já existentes, precarizando ainda mais as relações de trabalho.

Em contrapartida ao debate travado a partir das discussões envolvendo Giddens e a $E F$, notou-se, com a análise do mapeamento, maior número de publicações da área que 
utilizam os pensamentos de Giddens de maneira geral (76\%), ou seja, se limitam a tomar emprestados os conceitos do sociólogo apenas para realizarem uma leitura da sociedade moderna reflexiva, que, muitas vezes, não estabelecem relações aprofundadas com o objetivo proposto pelos textos analisados.

Por exemplo, Pimentel (2008) cita Giddens de maneira pontual para realizar uma leitura da sociedade contemporânea a partir das incertezas e dos novos contornos associados à noção de risco. Esta referência não faz diálogo com o objetivo do texto, que é "discutir como é construída a percepção de voar e como as sensações nos momentos ritualisticamente bem delineados de 'decolagem', 'voo' e 'aterrissagem' podem favorecer ou ser decorrentes de determinadas representações sociais" (p.26). O mesmo acontece com o texto de Dias (2012), que cita Giddens ao analisar o processo de transformação histórica da relação entre os índios e o esporte, mas não aprofunda como Giddens pode contribuir no processo de reflexividade estabelecido entre os agentes (índios e missionários) e o esporte. De modo similar, Schwartz et al. (2016), Cunha e Rezer (2015) e Lopez, Silveira e Stigger (2016) lançam mão de Giddens para realizarem uma leitura da sociedade, não estabelecendo diálogo com o campo da EF.?

Percebe-se, então, que as contribuições de Giddens para a EF se dividem entre: 1) uma leitura geral da sociedade atual e 2) possíveis diálogos que podem ser realizados a partir da discussão sobre o corpo e as políticas públicas voltadas para o esporte. A partir disso: quais são os usos e abusos que temos realizado a partir da obra deste autor? 0 que justifica as referências a Giddens quando a leitura é realizada de maneira geral?

Acredito que o campo da EF tem estabelecido duas relações com os pensamentos de Giddens. A primeira diz respeito à relação na qual Giddens tem servido a EF muito mais como apêndice do que como pensador importante para o campo. Nesse sentido, se retirássemos as citações de Giddens nos artigos mapeados, eles ainda manteriam o mesmo formato, sentido, estrutura, objetivos e conclusões. Assim, Giddens aparece exclusivamente como uma referência para demarcar o campo e/ou produzir segurança ontológica entre os pares.

A segunda relação se dá de maneira mais sólida, ou seja, a produção da EF parece se preocupar com os pensamentos de Giddens procurando, assim, tensionar suas teorias com questões pertinentes ao campo. É nessa relação que, como mostrado acima, torna-se interessante pensar o corpo no que tange à autoidentidade e as discussões a respeito do papel do esporte nas políticas públicas. Assim, Giddens aparece mais como uma referência para promover e suscitar a atividade epistemológica do campo. Atividade essa que, como destacado por Gonzáles e Fensterseifer (2005), permite a interrogação constante sobre o que é produzido na EF.

\section{CONCLUSÃO}

O objetivo deste texto foi mapear e analisar a presença de Anthony Giddens na produção científica da EF brasileira no século XXI. Ao realizar uma leitura geral da obra de Giddens a EF parece reconhecer, mesmo de forma superficial, que as transformações sociais diagnosticadas por este autor também afetam o seu campo. Assim, a leitura geral é importante, mas deve ser realizada com responsabilidade epistemológica. Em contrapartida, a leitura sobre

\footnotetext{
7 Pela limitação de páginas, torna-se inviável analisar todos os 29 artigos que fizeram uma leitura geral, contudo, vale a pena destacar um fato que ocorreu nos textos de Votre (2003) e Rechia (2005): ambos incluem Giddens nas referências, porém, sequer o citam durante seus respectivos textos.
} 
o corpo é fundamental, pois possibilita ver esse objeto por outra perspectiva, fazendo com que o corpo assuma um status de fenômeno que constitui a autoidentidade.

Aponto, em tom conclusivo, uma reflexão que pode ser realizada pelo campo da EF tendo os pensamentos de Giddens como alicerce. Tal reflexão advém da tentativa de pensar a escola e a EF dentro deste contexto, haja vista que nenhum dos textos mapeados se preocupou em realizar um diálogo de Giddens com a EF Escolar. Para Giddens (2001), as transformações sociais na modernidade tardia também passam a modificar as instituições educacionais. Segundo Giddens e Sutton (2016), o ensino escolar, ao mesmo tempo em que atua na reprodução das desigualdades sociais, também dota os indivíduos de conhecimentos e habilidades que permitem que eles possam superar e combater tais desigualdades.

De acordo com Giddens (2001), as escolas ainda são espaços fundamentais para os indivíduos se adaptarem às novas potencialidades hodiernas referentes, por exemplo, às diversas tecnologias. Nesse sentido, a presença da disciplina de EF também é fundamental, pois apresenta aos estudantes as novas possibilidades no que tange às práticas corporais contemporâneas como aquelas oriundas da natureza. Assim, Giddens nos ajuda na seguinte reflexão: como o estudante e a escola agem diante das transformações sofridas pelo campo da EF? O surgimento das práticas corporais de aventura e dos jogos digitais é recebido pelos estudantes e pela EF Escolar de forma reflexiva?

Por fim, devemos sempre lembrar daquilo que há mais de 15 anos vem sendo ressaltado pelo professor Valter Bracht: é preciso refletir sobre os termos e conceitos que temos pegado emprestados da Sociologia (e de outras ciências), pois, num futuro breve, poderemos correr 0 risco de nadarmos em um mar de superficialidade e acabarmos morrendo na praia.

\section{REFERÊNCIAS}

ALMEIDA, Felipe Quintão; BRACHT, Valter; VAZ, Alexandre. Classificações epistemológicas na Educação Física: redescrições... Movimento, v.18, n.4, p. 241-263, ago. 2012.

BRACHT, Valter. Sociologia Crítica do Esporte: uma introdução. 3. ed. ljuí: Unijui, 2005.

CUNHA, Antônio Camilo; REZER, Ricardo. Educação física e investigação: o elogio ao cuidado: uma carta aberta. Pensar a prática, v. 18, n. 3, p. 1-18, jul./set. 2015.

DIAS, Cleber. A Igreja, o Estado e a bola: história do esporte entre os índios do Brasil Central. Pensar a Prática, v. 15, n. 1, p. 148-175, jan./mar. 2012.

FORELL, Leandro; STIGGER, Marco Paulo. Trabalho voluntário em políticas públicas sociais de esporte e lazer: uma análise a partir de casos do Programa Escola Aberta. Revista Brasileira de Ciência do Esporte, v. 39, n. 1, p. 24-30, mar. 2017.

GIDDENS, Anthony. As consequências da modernidade. São Paulo: Editora UNESP, 1991.

GIDDENS, Anthony. Modernidade e identidade. Rio de Janeiro: Zahar, 2002.

GIDDENS, Anthony. A terceira via e seus críticos. Rio de Janeiro: Record, 2001. 
GIDDENS, Anthony. A constituição da sociedade. 3.ed. São Paulo: Martins Fontes, 2009.

GIDDENS, Anthony; SUTTON, Philip W. Conceitos Essenciais da Sociologia. São Paulo, UNESP, 2016.

GOMES, Ivan Marcelo. E se Ivan llitch fizesse atividade física? Reflexões sobre tormentos modernos. Pensar a Prática, v. 1, n. 12, p.1- 11, jan./abr. 2009.

GOMES, Ivan Marcelo. Obesidade como metáfora contemporânea: uma cruzada saudável em nome do consumo e do risco. Movimento, v. 12, n. 3, p. 45-71, set. 2006.

GOMES, Ivan Marcelo; PICH, Santiago; VAZ, Alexandre Fernandez. Sobre algumas vicissitudes de noção de saúde na sociedade dos consumidores. Revista Brasileira de Ciências do Esporte, v. 27, n. 3, p. 137-151, 2006.

GOMES, Ivan Marcelo; VAZ, Alexandre Fernandez; ASSMANN, Selvino José. Conselheiros midiáticos: o "caderno equilíbrio" da Folha de S. Paulo e suas ponderações na formação do indivíduo saudável. Movimento, v. 16, n. 4, p. 117-134, out./dez. 2010.

GOMES, Ivan Marcelo; ALMEIDA, Felipe Quintão; VAZ, Alexandre F. Sobre corpo, reflexividade: um diálogo entre Anthony Giddens e Michel Foucault. Política \& Sociedade, v.8, n.15, p.299-319, out.2009.

GONZÁLES, Fernando Jaime; FENSTERSEIFER, Paulo Evaldo. (org). Dicionário Crítico de educação física. ljuí: Ed. Unijuí, 2005. (Coleção educação física).

LAKATOS, Eva Maria; MARCONI, Mariana Andrade. Técnicas de pesquisa. 6. ed. São Paulo: Atlas, 2006.

LIMA, Homero Luís Alves de. Pensamento Epistemológico da Educação Física brasileira: das controvérsias acerca do estatuto científico. 164f. 1999. Dissertação (Mestrado em Educação) Universidade Federal de Pernambuco, Recife, 1999.

LOPEZ, Luiza Azevedo; SILVEIRA, Raquel da; STIGGER, Marco Paulo. O campo da Educação Física visto a partir da produção acadêmica sobre voleibol. Revista Brasileira de Ciência do Esporte, v. 38, n. 3, p. 235-242, set. 2016.

MEDEIROS, Cristina Carta Cardoso; GODOY, Letícia. As referências de Pierre Bourdieu e Norbert Elias na Revista Brasileira de Ciências do Esporte: mapeando tendências de apropriação e de produção de conhecimento na área da Educação Física (1979-2007). Revista Brasileira de Ciências do Esporte, v. 30, n. 2, p.199-214, 2009.

PIMENTEL, Giuliano Gomes. Ritos e risco na prática do vôo livre. Movimento, v.14, n. 3, p. 13-32, 2008.

PINTO, Sayonara Carla et al. Identidade(s) feminina(s) e cuidado de si na revista ag. Motrivivência, n. 39, p. 113-128, dez. 2012.

RECHIA, Simone. Espaço e planejamento urbano na sociedade contemporânea: políticas públicas e a busca por uma marca identitária na cidade de Curitiba. Movimento, v. 11, n. 3, p. 49-66, 2005.

SANTOS, Boaventura Souza. Um discurso sobre as ciências. 7.ed. São Paulo: Cortez, 2010.

SCHWARTZ, Gisele Maria et al. Estratégias de participação da mulher nos esportes de aventura.

Revista Brasileira de Ciências do Esporte, v. 38, n. 2, jun. 2016. 
SETTON, Margarida. A teoria do habitus em Pierre Bourdieu: uma leitura contemporânea. Revista brasileira de Educação, n.20, p.60-70, 2002.

SILVA, Carlos Alberto da; CORREIA, Adriana. Espetáculo e reflexividade: a dimensão estética do basquete de rua. Revista Brasileira de Ciência do Esporte, v. 30, n. 1, p. 107-122, set. 2008.

SOUZA, Carlos Eduardo de. Estado cosmopolita, organismos internacionais e a terceira via: o esporte enquanto política social. Motrivivência, v. 26, n. 42, p. 41-54, jul. 2014.

SOUZA, Juliano de; MARCHI JÚNIOR, Wanderley. Por uma sociologia reflexiva do esporte: considerações teórico-metodológicas a partir da obra de Pierre Bourdieu. Movimento, v. 16, n. 1, p. 293-315, dez. 2010.

SOUZA, Juliano de; MARCHI JÚNIOR, Wanderley. Bourdieu e a sociologia do esporte: contribuições, abrangência e desdobramentos teóricos. Tempo Social, v. 29, n. 2, p. 243-286, ago. 2017.

TEIXEIRA, Fábio Luís Santos; FREITAS, Clara Maria Silvestre de; CAMINHA, Iraquitan de Oliveira. A beleza feminina como poder: desvendando outros sentidos para a construção estética de si. Revista Brasileira de Ciência do Esporte, v. 36, n. 2, p. 485-500, jun. 2014.

VOTRE, Sebastião Josué. $O$ estado da arte nos estudos sobre discurso, conteúdo e significado na Educação Física. Movimento, v. 9, n. 1, p. 47-65, jan./abr. 2003. 